\title{
Executive compensation and competitive pressure in the product market: How does firm entry shape managerial incentives?*
}

\author{
Kanișka Dam ${ }^{\dagger} \quad$ Alejandro Robinson-Cortés ${ }^{\ddagger}$
}

July 17, 2019

\begin{abstract}
Motivated by empirical evidence, we develop an incentive contracting model under oligopolistic competition to study how incumbent firms adjust managerial incentives following deregulation policies that enhance competition. We show that firms elicit higher managerial effort by offering stronger incentives as an optimal response to entry, as long as incumbent firms act as production leaders. Our model draws a link between an industry-specific feature, the time needed to build production capacity, and the effect that product market competition has on executive compensation. We offer novel testable implications regarding how this industry-specific feature shapes the incentive structure of executive pay.
\end{abstract}

JEL codes: D43, D86, J33

Keywords: Competition; Firm entry; Managerial incentives.

\footnotetext{
*We thank Archishman Chakraborty, Enrique Garza, Sonia Di Giannatale, Sergio Montero, Luciana Moscoso, Arijit Mukherjee, Kostas Serfes, Matt Shum and Leeat Yariv for helpful suggestions.

${ }^{\dagger}$ Corresponding author. Center for Research and Teaching in Economics (CIDE), 3655 Carretera Mexico-Toluca, Lomas de Santa Fe, 01210 Mexico City, Mexico. E-mail: kaniska.dam@cide.edu

$\ddagger$ Division of Humanities and Social Sciences, California Institute of Technology, 1200 East California Blvd. Pasadena, CA 91125. E-mail: alejandro@caltech.edu
} 


\section{Introduction}

There is a plethora of empirical evidence that supports the Hicksian view (Hicks, 1935) that executive compensation tends to be more performance-sensitive in more competitive environments (e.g. Nickell, 1996; Van Reenen, 2011). A series of empirical studies have used industry-specific regulatory reforms to analyze the effect of competition on executive pay (Crawford, Ezzell, and Miles, 1995; Hubbard and Palia, 1995; Kole and Lehn, 1999; Palia, 2000; Cuñat and Guadalupe, 2009a; Dasgupta, Li, and Wang, 2017). These studies focus on how deregulation policies that increases competition in the product market affect the structure of managerial incentive contracts. The main takeaway from this literature is that, following a deregulation policy that intensifies product market competition, firms reduce managerial slack by increasing executive compensation and strengthening its pay-performance sensitivity.

Our objective in this paper is to explain the nature of the aforementioned regularity, and to offer new insights into how it is shaped by industry-specific features. First, we provide a simple model of oligopolistic competition with firm entry that shows why incumbent firms find it optimal to reduce managerial slack when competition rises due to deregulation. Then, we use our model to derive novel empirical implications regarding the time to build production capacity in an industry. Our model shows that this industry-specific feature is a crucial factor when analyzing the effect that firm entry has on executive compensation. According to our model, the relationship observed in the empirical studies obtains only in industries in which the time to build capacity is such that incumbents act as production leaders and entrants as followers. This result goes in line with the empirical literature given that existing studies focus on industries in which it takes time to build production capacity, such as banking, manufacturing, and the airline industry.

The question of how product market competition shapes managerial incentives is far from new in the literature. ${ }^{1}$ Notwithstanding, our approach is novel in that we analyze it explicitly in a framework of firm entry. Because incumbent firms anticipate (and accommodate) future entry with relaxing regulation, we use a standard model of sequential quantity-setting oligopoly, in which entrant firms choose their managerial contracts and quantities after observing those of the incumbents. Our focus is on the strategic response of incumbents regarding managerial incentive pay as they foresee the entry of new firms. In line with the the empirical literature, our main finding is that it is optimal for incumbents to strengthen incentive pay and reduce managerial slack when they foresee the entry of new firms into the product market. Moreover, we show that the strength of the managerial incentives offered by incumbents is increasing in the number of entrants - higher competitive pressure leads to steeper incentives and lower managerial slack.

To highlight the role played by the time to build production capacity, we also analyze the case in which the entrant firms set quantities and contracts along with the incumbents, instead of after them. Accordingly, our sequential setting, in which entrants set contracts and quantities after the incumbents, corresponds to industries in which it takes time to build production capacity (Allen, Deneckere, Faith, and Kovenock, 2000). The simultaneous one, in which entrants set them along with the incumbents, corresponds to industries in which the time to build capacity is negligible (Kreps and Scheinkman, 1983). In the latter setting we find that the relationship between competition and managerial incentives is reversed: incumbents find it optimal to offer weaker incentives to their managers, irrespective of the number of new firms entering the market. Notably, this setting is equivalent to one in which the number of incumbents

\footnotetext{
${ }^{1}$ The notion that monopoly, and market power in general, are detrimental to managerial efficiency dates back to Smith (1776, Book 1, Chapter 11), and has a long tradition in the literature (Leibenstein, 1966; Hart, 1983; Scharfstein, 1988).
} 
varies in a cross-section, i.e., to comparing two markets facing the same amount of entry that differ in their original levels of competition. Under this light, our second result goes in line with previous literature which analyzes the effect of competition using comparative statics in the number of firms, instead of via firm entry (e.g. Martin, 1993; Hermalin, 1994; Golan et al., 2015).

Our model incorporates managerial incentive contracts into the Stackelberg quantity competition framework proposed by Daughety (1990). There is a fixed number of incumbents and a set of potential entrants with more entrants meaning greater competitive pressure on the incumbent firms. Both incumbents (in the pre-entry stage) and entrants (in the post-entry stage) play Cournot games among themselves; entrants take the aggregate output of incumbents as given. All firms are initially inefficient, and each hires a risk neutral manager whose principal task is to exert non-verifiable R\&D effort to bring down the constant marginal cost of production, what is often termed "process innovation." We assume that the final realizations of marginal costs are private information among firms, and that incentive contracts are publicly observable. Hence, even though the marginal costs of rival firms are unknown, each firm observes a signal of how likely every other firm is to reduce its marginal cost.

The crux of our analysis is that managerial effort is beneficial to incumbents in two ways. First, steeper incentives that induce each manager to exert higher effort directly increase the likelihood of a cost reduction (value-of-cost-reduction effect). Second, they also alter the beliefs of the rival firms about the true cost realization of a given firm (marginal-profitability-of-effort effect). Even if a manager fails to achieve the cost target, her effort is profitable in as much as it makes the rivals believe that cost reduction has actually been attained. More intensified product market competition affects each of these two through the market size and the effective size of cost reduction. As the entrants' optimal contracting and production decisions are directly negatively affected by the aggregate incumbent output, the entry of new firms implies an increase in both market size and the effective size of cost reduction for incumbents. In turn, this implies both a higher expected value of cost reduction and expected marginal profitability of effort, which makes it optimal for incumbents to elicit higher managerial effort by strengthening incentives. It is worth noting that, even in the absence of the marginal-profitability-of-effort effect, a growing number of entrants strengthens the value-of-cost-reduction effect. Such case arises, for example, when marginal costs are public information and managerial effort is unprofitable beyond cost reduction.

We use our model to derive three testable implications related to the time to build production capacity in an industry. First, as mentioned earlier, firms in industries in which building capacity takes time strengthen their managerial compensation packages as an optimal response to the entry of new firms. However, the opposite obtains in industries in which production capacity may be acquired instantaneously. Second, regardless of the time to build capacity, the expected equilibrium price falls as new firms enter the market. However, it drops more rapidly, as more firms enter the market, in markets in which there is time to build capacity. This happens because incumbent firms reduce managerial slack by strengthening incentives and thus are more likely to lower production costs and increase output. Finally, although the profits of incumbent firms are decreasing in the number of entrants in markets with no time to build capacity, they are not so when substantial time is required to build capacity. That is, by strengthening managerial incentives, incumbent firms offset the loss in profits caused by more competition.

The paper is organized as follows. In Section 2, we review the related literature. In the next section, we outline the model. In Section 4, we solve for the equilibrium and present our main results. In Section 5, we present the testable implications of our model, and we conclude in Section 6. All proofs are relegated to Appendix B, most of which follow from Lemma 3 in Appendix A. 


\section{Related literature and our contribution}

The astounding rise in both the level and incentive component of executive compensation packages over the past three decades is often attributed to changes in industry configurations. The idea is based on the Darwinian view of organizations, which states that, in order to survive and perform well, firms must solve governance problems by adapting their structure of managerial incentive contracts as product market competition rises. As mentioned in the previous section, several studies have exploited regulatory reforms to analyze how product market competition shapes the incentive structure of the executive compensation packages. Kole and Lehn (1999), and Palia (2000) study how the introduction of the Airline Deregulation Act in 1978 has altered the structure of the incentive contracts offered to CEOs in the U.S. airline industry. Crawford et al. (1995), Hubbard and Palia (1995), and Cuñat and Guadalupe (2009a), analyze the changes in executive pay in the U.S. banking sector following an important regulatory reform that permitted interstate banking during the 1980s. In the context of international trade, Cuñat and Guadalupe (2009b) study the effect of changes in foreign competition on executive pay in the U.S. firms. Dasgupta et al. (2017) analyze the effect of industry-level tariff cuts on CEOs pay-performance sensitivity in the U.S. manufacturing sector. Overall, these studies confirm the view that one of the ways in which firms react to intensifying product-market competition is by increasing the pay-performance sensitivity of their executive compensation packages. ${ }^{2}$

In agency theoretic models relating product market competition to managerial incentives, competing against more firms invariably reduces equilibrium output and profits. ${ }^{3}$ In turn, this lowers the value of attaining a cost reduction and thus makes it optimal to offer waker managerial incentives (the so-called scale or output effect). In a framework of hidden information (about the realization of marginal costs), Martin (1993) assumes that the marginal productivity of managerial effort decreases in the number of active firms in a Cournot market, and hence, the equilibrium state-contingent contracts provide weaker incentives as the number of firms grows. Golan, Parlour, and Rajan (2015) also analyze managerial incentives in a Cournot oligopoly. As the expected product market profit of each firm depends on the likelihood of achieving a low marginal cost in the rival firms, the observed profit as a signal of managerial effort becomes noisier, and hence, the cost of incentive provision magnifies in a more competitive environment. This effect points in the same direction as the standard scale effect implying a negative association between competition and incentives.

In order to counteract the negative effect of competition on managerial incentives due to lower product market profits, one thus requires to identify additional countervailing effects of product market competition on managerial incentives. The effect of competition on executive pay-performance sensitivity may be, in theory, non-monotonic. Hermalin (1992) models CEOs as receiving a fraction of the shareholder income. Because more intense competition erodes this income, managers tend to consume fewer "agency goods", i.e., expend more effort, as agency goods are assumed to be normal goods. Hermalin (1994) assumes that more firms in a Cournot market implies an exogenous decrease in the slope of the inverse market demand (with the intercept remaining constant), and hence, an exogenous increase in the market size of each firm is identified as a countervailing business stealing effect, apart from the standard value-of-cost-reduction effect. Schmidt (1997) shows that if a firm is more likely to go bankrupt in a more competitive environment, the manager tends to work harder to avoid liquidation of the firm's assets as

\footnotetext{
${ }^{2}$ In a related study, Karuna (2007) also finds a positive relationship between the degree of product substitutability and stock options granted to CEOs.

${ }^{3}$ See Legros and Newman (2014) for an excellent survey of the extant literature.
} 
liquidation implies a loss of reputation. The value-of-cost-reduction effect and the threat-of-liquidation effect do not often point in the same direction. Piccolo, D'Amato, and Martina (2008) build on Martin (1993), and identify an agency effect. In their model, profit-sharing contracts improve productive efficiency, which points in the opposite direction of the standard scale effect. They obtain an inverted-U relationship between competition and managerial effort. Raith (2003) analyzes a managerial incentive problem in a price-setting oligopoly with horizontal differentiation and privately realized marginal costs. He establishes a positive association between competition and managerial incentives by showing that in a free-entry equilibrium managerial incentives increase due to a higher degree of product substitutability, market size or lower cost of entry. Wu (2017) analyzes the interaction between product and labor markets in a model that assigns worker talent to heterogeneous firms. Greater product market competition, as measured by demand elasticity, results in a reallocation of more talented managers from smaller to larger firms, and hence, an increase in the value of managerial efforts in such firms. Consequently, firms strengthen managerial incentives, and the resulting wage distribution becomes more right-skewed.

Our approach is novel because we analyze a new mechanism through which product market competition affects executive pay-performance sensitivity. In particular, we study how incumbent firms adjust their managerial contracts optimally when new firms are about to enter the market. As mentioned earlier, a model of sequential quantity competition is appropriate to analyze the effect of increased competition following a regulatory reform. In line with the empirical evidence, we find a positive relationship: as competition rises, incumbents find it optimal to strengthen executive pay-performance sensitivity in order to reduce managerial slack. Furthermore, we also contribute to the literature by noting that the time to build production capacity in an industry is a key factor in studying how competition affects managerial incentives. In particular, it allows us to relate our model to the earlier literature that find a negative association between competition and managerial incentives. Therefore, our analysis adds to previous literature and conforms to empirical findings.

\section{The model}

\subsection{Specifications}

The economy consists of two classes of risk neutral agents, $n+m$ ex-ante identical firms who compete in quantities in a market for a homogeneous good, and $n+m$ ex-ante identical managers. The firms are divided in two groups-namely, a subset $I$ of $n \geq 1$ incumbents and a subset $J$ of $m \geq 0$ entrants, with $I \cap J=\varnothing$. Our main objective is to analyze the effect of increased competition, i.e., an increase in $|J|=m$, on the optimal managerial contracts in the firms that belong to $I$. Until section 4.5 , where we analyze cross-sectional variation in the number of incumbents, we consider $I$ as a fixed collection of incumbent firms. A typical incumbent firm is denoted by $i$, and a typical entrant, by $j$. Often for convenience we will denote a generic firm (incumbent or entrant) by $k \in I \cup J$ with $|I \cup J|=n+m$.

Let $q_{k}$ denote the production of firm $k$. The inverse market demand is given by $P=1-Q$, where $Q$ denotes the aggregate industry output, and $P$ the market price. Each firm $k$ operates on a constant-returnsto-scale production technology with marginal $\operatorname{cost} c_{k} \in\{0, c\}$ where $0<c<1$. Initially, all firms have the inefficient technology, i.e., $c_{k}=c$ for all $k$. Each firm hires a manager whose principal task is to exert non-verifiable R\&D effort in order to mark down the marginal cost to 0 . The probability that the marginal cost is reduced is given by $e_{k}$, which is the effort exerted by the manager of firm $k$. Each firm $k$ offers its 
manager a take-it-or-leave-it contract $\left(w_{k}(0), w_{k}(c)\right)$ which is contingent on the realized marginal cost $c_{k} \in\{0, c\}$. Contracts are subject to limited liability of the managers. Managerial contracts are publicly observable, but the realized marginal costs remain private information of the firms. Every manager has the same effort cost function $\psi(e)=e^{2} / 2$, and her outside option is normalized to 0 .

\subsection{Timing of events}

The timing of events, which is divided into two phases, is described in Figure 1. At date 1, the incumbents hire a manager apiece by offering publicly observable contingent contracts. At $t=2$, the manager at each incumbent firm exerts non-verifiable effort, and the marginal cost of each incumbent is privately realized. At $t=3$, the incumbents simultaneously set quantities. After observing the aggregate quantities set by the incumbents, the entrants repeat the timing at dates $t=1^{\prime}, 2^{\prime}, 3^{\prime}$. Finally, after date $t=3^{\prime}$, the market price is set, and the profits of all firms (incumbents and entrants) are realized.

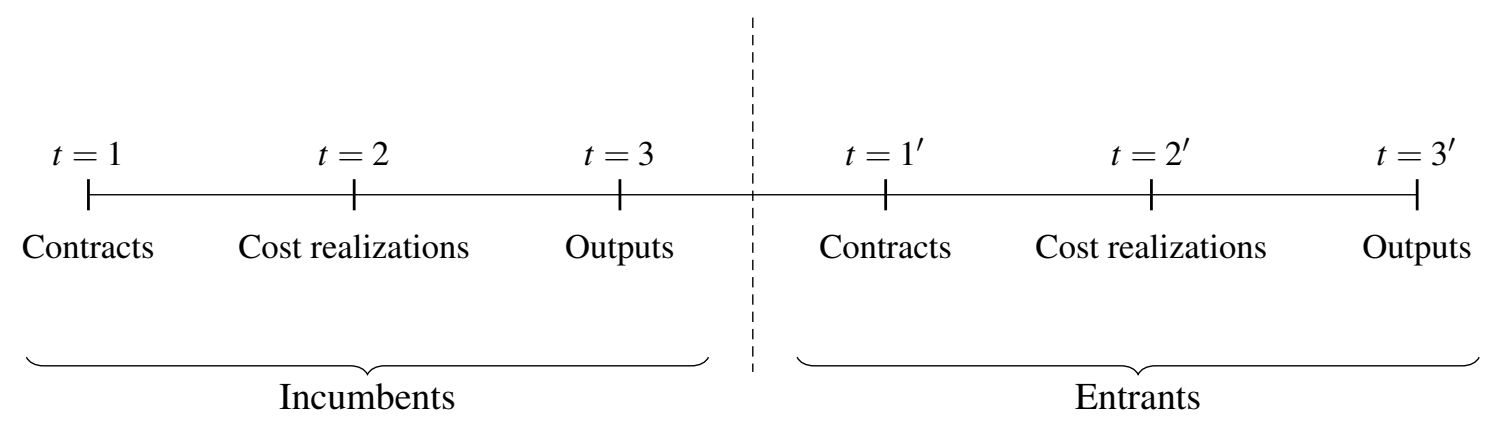

Figure 1: The timing of events in the sequential quantity-setting oligopoly.

\subsection{Managerial contract and effort}

Each manager $k$ chooses her effort $e_{k}$ optimally, given the contracts $w_{k}(0)$ and $w_{k}(c)$ at firm $k$. Because the realizations of marginal costs are independent, managerial contracts at each firm $k$ are independent of the realizations of marginal costs at the rival firms. The optimal effort at firm $k$ is given by:

$$
e_{k}=\underset{\hat{e}_{k}}{\operatorname{argmax}}\left\{\hat{e}_{k} w_{k}(0)+\left(1-\hat{e}_{k}\right) w_{k}(c)-\frac{1}{2} \hat{e}_{k}^{2}\right\}=w_{k} \equiv w_{k}(0)-w_{k}(c) \text {. }
$$

The above is the incentive compatibility constraint of the manager at firm $k$ in which $w_{k}$ represents the incentive component of the managerial contract. Therefore, we will refer to a higher (lower) value of $w_{k}$, or equivalently, of $e_{k}$ as 'stronger (weaker) managerial incentives'. We assume limited liability (non-negative income for the manager at each state of nature), i.e.,

$$
w_{k}(c) \geq 0, \quad \text { and } \quad w_{k}(0) \geq 0 .
$$

Finally, the expected utility of the manager at each firm $k$ must be at least as high as her outside option 0 , i.e., the participation constraint of the manager is given by:

$$
u_{k} \equiv e_{k} w_{k}(0)+\left(1-e_{k}\right) w_{k}(c)-\frac{1}{2} e_{k}^{2} \geq 0 .
$$




\subsection{Quantity competition}

We follow Daughety (1990), which is a generalization of the standard notion of Stackelberg competition, to model market competition in the present context. After managers have exerted effort, each incumbent $i$ learns its marginal cost $c_{i}$ privately. Then, the incumbent firms (the "leaders") choose quantities $\left(q_{1}, \ldots, q_{n}\right)$ simultaneously to maximize expected profit. After observing the aggregate incumbent quantity, $Q_{I} \equiv \sum_{i \in I} q_{i}$, the entrants choose managerial contracts simultaneously, taking $Q_{I}$ as given. Following the choice of managerial effort, $e_{j}$, each entrant firm $j$ learns its marginal cost $c_{j}$ privately. Finally, the entrant firms (the "followers") choose quantities $\left(q_{1}, \ldots, q_{m}\right)$ in a Cournot fashion to maximize expected profit. We assume that in equilibrium all $m$ entrants decide to enter, i.e., regardless of their own and the incumbents' cost realizations, each entrant finds it optimal produce a positive output in equilibrium. This rules out the possibility that the incumbents may deter entry. The incumbents are also assumed to produce a positive output in equilibrium regardless of their realized marginal cost. This implies a restriction of the parameter space-namely, an upper bound on $c$. This is an innocuous but conservative assumption as the incentives to attain a low marginal cost would have been stronger otherwise. We solve for the equilibrium by backward induction, and show that it is unique, and symmetric for incumbents and entrants.

\section{Managerial incentives in sequential oligopoly}

\subsection{Choice of quantities and managerial efforts by the entrants}

Let $Q_{J}=\sum_{j \in J} q_{j}$ be the aggregate entrant output, and $q_{-j} \equiv Q_{J}-q_{j}=\sum_{k \in J \backslash\{j\}} q_{k}$, the aggregate output of the rival entrants. Further, let the managerial effort and bonus vectors be denoted by $\left(e_{i}, e_{j}\right)$ and $\left(w_{i}, w_{j}\right)$, respectively for $i \in I$ and $j \in J$. At the quantity setting stage, $t=3^{\prime}$, each entrant $j$ takes $Q_{I}$ and $q_{-j}$ as given to solve

$$
\max _{q_{j}} q_{j}\left(1-Q_{I}-q_{j}-\mathbb{E} q_{-j}-c_{j}\right) .
$$

The subgame played by the entrants at the the quantity setting stage, $t=3^{\prime}$, is simply a Cournot game among $m$ firms with a residual demand $P=1-Q_{I}-\sum_{j \in J} q_{j}$. The quantity of each rival entrant is a random variable because its realized marginal cost is unknown to entrant firm $j$. The expected cost of firm $j$ is $\mathbb{E} c_{j}=c\left(1-e_{j}\right)$, where $e_{j}$ is the incentive compatible level of managerial effort chosen at date $t=2^{\prime}$. Because the managerial contracts of all entrant firms are publicly observable, every firm $j$ knows the expected cost of every rival firm. Further, let $e_{-j} \equiv \sum_{k \in J \backslash\{j\}} e_{k}$. The quantity and profit of each entrant firm in the subgame perfect equilibrium are respectively given by:

$$
\begin{aligned}
& q_{j}\left(c_{j}, e_{j}, e_{-j}, Q_{I}\right)=\frac{2\left(1-Q_{I}\right)-(m+1) c_{j}+(m-1) c\left(1+e_{j}\right)-2 c e_{-j}}{2(m+1)}, \\
& \pi_{j}\left(c_{j}, e_{j}, e_{-j}, Q_{I}\right)=\left\{\frac{2\left(1-Q_{I}\right)-(m+1) c_{j}+(m-1) c\left(1+e_{j}\right)-2 c e_{-j}}{2(m+1)}\right\}^{2} .
\end{aligned}
$$

Note that $\pi_{j}\left(c_{j}, e_{j}, e_{-j}, Q_{I}\right)$ is the expected market profit of each entrant firm $j$ conditional on its realized cost, $c_{j}$. It depends on $e_{j}$ even when conditioning on $c_{j}$ because the effort exerted by the manager at firm $j$ pins down the beliefs of the rival entrants about $c_{j}$. These beliefs affect the rivals' output decisions in the same way as $e_{-j}$ affects those of firm $j$, so the effort exerted by the manager at firm $j$ is profitable 
beyond its cost realization. If the realized marginal costs were publicly observable, the product market profits would not depend on managerial efforts; instead, they would depend on the observed numbers of high- and low-cost firms (cf. Golan et al., 2015), and managerial effort would not be profitable beyond the value of cost reduction.

The optimal contracting problem at $t=1^{\prime}$ at each entrant firm $j$ is solved in two stages (e.g. Grossman and Hart, 1983). First, firm $j$ minimizes the expected incentive costs in order to implement a given level of effort subject to the constraints described in Section 3.3, i.e.,

$$
C_{j}\left(e_{j}\right)=\min _{\left\{w_{j}(0), w_{j}(c)\right\}} e_{j} w_{j}(0)+\left(1-e_{j}\right) w_{j}(c),
$$

subject to (IC), (LL) and (PC).

The value function, called the 'incentive cost function', of the above minimization problem is given by:

$$
C_{j}\left(e_{j}\right)=C\left(e_{j}\right)=e_{j}^{2} \quad \text { for all } j \in J .
$$

In the second stage, firm $j$ chooses the effort level $e_{j}$ in order to maximize the expected profits

$$
\Pi_{j}\left(e_{j}, e_{-j}, Q_{I}\right) \equiv e_{j} \pi_{j}\left(0, e_{j}, e_{-j}, Q_{I}\right)+\left(1-e_{j}\right) \pi_{j}\left(c, e_{j}, e_{-j}, Q_{I}\right)
$$

net of its incentive costs $C\left(e_{j}\right)$, i.e.,

$$
\max _{e_{j}} \Pi_{j}\left(e_{j}, e_{-j}, Q_{I}\right)-C\left(e_{j}\right) .
$$

Let the equilibrium managerial effort in the entrant firms be denoted by $e_{J}\left(Q_{I}, m\right)$, which is derived from the first-order condition of the maximization problem $\left(\operatorname{Max}_{j}\right)$. It is analyzed in the following lemma.

Lemma 1 Given the aggregate output $Q_{I}$ of the incumbent firms, the equilibrium managerial effort in the entrant firms is unique, symmetric, and is given by:

$$
e_{J}\left(Q_{I}, m\right)=\frac{c\left[8 m\left(1-Q_{I}\right)+c\left(m^{2}-6 m+1\right)\right]}{2\left[4(m+1)^{2}+c^{2}(m-1)^{2}\right]} \text { for all } j \in J
$$

The higher the aggregate output of the incumbents, $Q_{I}$, the lower is the managerial effort in each entrant firm. This is because when the aggregate output of the incumbents expands, the entrants face a shrunken residual demand, and hence, it is optimal for each of them to offer weaker incentives to its manager, which elicit lower effort.

\subsection{Quantity choice of the incumbents}

In setting quantities, the incumbents take into account the best response of the entrant firms and anticipate their managerial efforts. Let $q_{j}\left(c_{j}, e, Q_{I}\right)$ denote the quantity of an entrant firm $j$ in the subgame perfect equilibrium for a common level of effort $e$ (among the entrants), i.e., with $e_{j}=e$ for all $j \in J$. Then, the expected aggregate output of the entrants is given by:

$$
\begin{aligned}
Q_{J}\left(Q_{I}, m\right) & =\sum_{j \in J} \mathbb{E} q_{j}\left(c_{j}, e_{J}\left(Q_{I}, m\right), Q_{I}\right) \\
& =\kappa(m)\left(C_{1}-C_{2} Q_{I}\right),
\end{aligned}
$$


where

$$
\kappa(m) \equiv \frac{m(m+1)}{4(m+1)^{2}+c^{2}(m-1)^{2}}
$$

is an increasing function in $m$, and $C_{2} \equiv 4+c^{2}$ and $C_{1} \equiv C_{2}-c\left(4+c^{2} / 2\right)$ are positive constants that depend on $c$. Note that the aggregate best response is linear in the aggregate incumbent quantity $Q_{I}$, and it shifts upward as $m$ grows as $\kappa^{\prime}(m)>0$. Importantly, the cross-derivative $\partial^{2} Q_{J}\left(Q_{I}, m\right) / \partial m \partial Q_{I}=$ $-C_{2} \kappa^{\prime}(m)<0$, which means that the incumbents output softens the impact of firm entry on the market price. As the incumbent firms behave in a Cournot fashion, each incumbent firm $i$ solves the following maximization problem at date $t=3$ :

$$
\begin{aligned}
& \max _{q_{i}} q_{i}\left(1-q_{i}-\mathbb{E} q_{-i}-Q_{J}\left(q_{i}+\mathbb{E} q_{-i}, m\right)-c_{i}\right) \\
\Longleftrightarrow & \max _{q_{i}} q_{i}\left(A(m)-B(m)\left(q_{i}+\mathbb{E} q_{-i}\right)-c_{i}\right),
\end{aligned}
$$

where $A(m) \equiv 1-C_{1} \kappa(m)$ and $B(m) \equiv 1-C_{2} \kappa(m)$. From the incumbents' perspective, entry of new firms implies two countervailing effects. On the one hand, more firms implies a lower market price, i.e., $A(m)<1$. However, as the aggregate incumbent output diminishes the optimal effort and output of entrants, it also implies that the price is less responsive to the incumbents output, i.e., $B(m)<1$. This gives them more leeway; they can increase output without reducing the equilibrium price too much. For reasons that will become clear below, it is convenient to consider these effects in a different but equivalent way. Note that the solution to (1) is equivalent to the solution of the following 'normalized' problem:

$$
\max _{q_{i}} q_{i}\left(a(m)-\left(q_{i}+\mathbb{E} q_{-i}\right)-\theta(m) c_{i}\right)
$$

where

$$
a(m) \equiv \frac{A(m)}{B(m)}=\frac{1-C_{1} \kappa(m)}{1-C_{2} \kappa(m)}, \quad \theta(m) \equiv \frac{1}{B(m)}=\frac{1}{1-C_{2} \kappa(m)} \quad \text { with } \quad a^{\prime}(m), \theta^{\prime}(m)>0 .
$$

That is, from the perspective of each incumbent $i$, the entry of new firms is equivalent to an increase in the market size, $a(m)>1$, and the size of cost reduction, $\theta(m) c>c$. This means that, even though entrants reduce the market price, the market size increases from the incumbents perspective as the price is less responsive to their output. Which also equates to a higher size of cost reduction.

We depict the equivalence mentioned above graphically in Figure 2 by means of the marginal revenue (derived from the residual demand faced by $i$ ) and marginal cost curves. The solid downward sloping line is the marginal revenue function derived from the residual demand $\left[A(m)-B(m) \mathbb{E} q_{-i}\right]-B(m) q_{i}$ of incumbent $i$ for $m>0$. This marginal revenue function has a slope equal to $-2 B(m)$. The maximum price is represented by the point $A(m)-B(m) \mathbb{E} q_{-i}$, and the market size is represented by $a(m)-\mathbb{E} q_{-i}$. Hence, the horizontal intercept of the marginal revenue function is given by $\left[a(m)-\mathbb{E} q_{-i}\right] / 2$. If there were no entrants, we would have $A(0)=B(0)=1$. Following the entry of at least one firm, we have $A(m)<1$ and $B(m)<1$. The solid horizontal line is the marginal cost of a high-cost incumbent $i$. The equilibrium quantity $q_{i}(c, m)$ is determined by the intersection of the marginal revenue and marginal cost of the high-cost incumbent $i$ for a given number of entrants $m$. The normalized marginal revenue function that is derived from the normalized residual demand $a(m)-\mathbb{E} q_{-i}-q_{i}$ with $a(m)>1$, and the normalized marginal cost curve, $\theta(m) c$, are shown by the dashed lines. The normalized marginal revenue curve is steeper than the actual marginal revenue curve because it has a slope equal to -2 . These two normalized functions intersect at the same equilibrium output level $q_{i}(c, m)$ of each high-cost incumbent. For each 


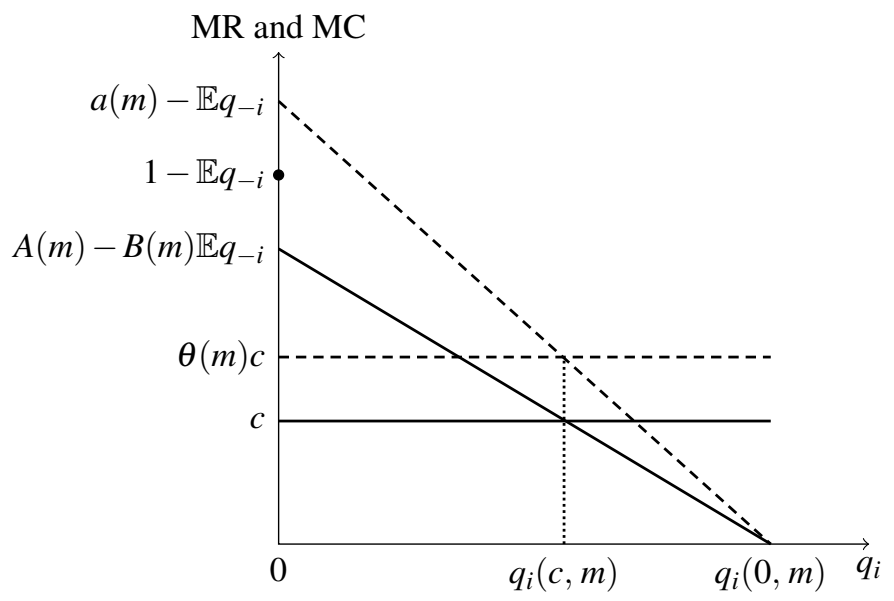

Figure 2: The optimal output of a representative incumbent firm for a given number of entrants under the actual (solid line) and normalized (dashed line) marginal revenue and cost functions.

low-cost incumbent, the equilibrium quantity is given by $q_{i}(0, m)=\left[a(m)-\mathbb{E} q_{-i}\right] / 2$ because for such a firm $i, c_{i}=\theta(m) c_{i}=0$.

Let $e_{-i}=\sum_{l \in I \backslash\{i\}} e_{l}$ be the aggregate managerial efforts of the rival incumbents. The equilibrium output and profit of incumbents are described in the following lemma.

Lemma 2 Given the number of entrants, $m$, the privately realized marginal costs $\left\{c_{1}, \ldots, c_{n}\right\}$, and the managerial efforts $\left\{e_{1}, \ldots, e_{n}\right\}$ at the incumbent firms, the equilibrium quantity and profit of each incumbent firm are respectively given by:

$$
\begin{aligned}
& q_{i}\left(c_{i}, e_{i}, e_{-i}, m\right)=\frac{2 a(m)-(n+1) \theta(m) c_{i}+(n-1) \theta(m) c\left(1+e_{i}\right)-2 \theta(m) c e_{-i}}{2(n+1)}, \\
& \pi_{i}\left(c_{i}, e_{i}, e_{-i}, m\right)=\left\{\frac{2 a(m)-(n+1) \theta(m) c_{i}+(n-1) \theta(m) c\left(1+e_{i}\right)-2 \theta(m) c e_{-i}}{2(n+1)}\right\}^{2} .
\end{aligned}
$$

Although the equilibrium quantity and profit of each entrant $j$ depend on the aggregate incumbent quantity $Q_{I}$, those of each incumbent firm $i$ do not depend on the entrant quantity because the incumbents act as Stackelberg leaders in the product market. But they do depend on the number of entrants via the market size $a(m)$ and the size of cost reduction $\theta(m) c$ for the incumbent firms.

\subsection{Equilibrium managerial efforts and incentives in the incumbent firms}

In the contracting stage at date 1 , each incumbent firm $i$ solves a maximization problem similar to $\left(\operatorname{Max}_{j}\right)$ (replace $j$ by $i$ everywhere, and drop $Q_{I}$ from the profit function). Define by $\Delta \pi_{i}\left(e_{i}, e_{-i}, m\right) \equiv$ $\pi_{i}\left(0, e_{i}, e_{-i}, m\right)-\pi_{i}\left(c, e_{i}, e_{-i}, m\right)$ the expected value of cost reduction of each incumbent firm $i$. The first-order condition for the contracting problem of each incumbent $i$ is given by:

$$
\frac{\partial \Pi_{i}\left(e_{i}, e_{-i}, m\right)}{\partial e_{i}} \equiv \Delta \pi_{i}\left(e_{i}, e_{-i}, m\right)+\left[e_{i} \frac{\partial \pi_{i}\left(0, e_{i}, e_{-i}, m\right)}{\partial e_{i}}+\left(1-e_{i}\right) \frac{\partial \pi_{i}\left(c, e_{i}, e_{-i}, m\right)}{\partial e_{i}}\right]=2 e_{i} . \quad\left(\mathrm{FOC}_{i}\right)
$$


At the optimal managerial effort, the marginal benefit of effort is equalized with the marginal incentive cost. The left-hand-side of $\left(\mathrm{FOC}_{i}\right)$ is the marginal benefit of effort which comprises of two termsnamely, the expected value of cost reduction, $\Delta \pi_{i}\left(e_{i}, e_{-i}, m\right)$, and the expected marginal profitability of effort, $\mathbb{E}\left[\partial \pi_{i}\left(c_{i}, e_{i}, e_{-i}, m\right) / \partial e_{i}\right]$. On the right-hand-side of the above equation is the marginal incentive cost, $C^{\prime}\left(e_{i}\right)$. Let the equilibrium managerial effort and incentives of incumbents be denoted by $e_{I}(m)$ and $w_{I}(m)$, respectively, which are determined from $\left(\mathrm{FOC}_{i}\right)$ and $(\mathrm{IC})$. Note also that the manager's utility, i.e., the net level of compensation of the manager in each incumbent firm is given by:

$$
u_{I}(m) \equiv e_{I}(m) w_{I}(m)-\frac{1}{2}\left(e_{I}(m)\right)^{2}=\frac{1}{2}\left(w_{I}(m)\right)^{2} .
$$

The following proposition describes the equilibrium managerial effort, incentives, and the level of executive compensation in the incumbent firms.

Proposition 1 The equilibrium managerial effort and incentives at the incumbent firms are unique, symmetric, and given by:

$$
e_{I}(m)=w_{I}(m)=\frac{\theta(m) c\left[8 a(m) n+\theta(m) c\left(n^{2}-6 n+1\right)\right]}{2\left[4(n+1)^{2}+\{\theta(m) c\}^{2}(n-1)^{2}\right]} \in(0,1) .
$$

The equilibrium utility accrued to each manager at the incumbent firms is given by $u_{I}(m)$, as in (2). Moreover, for fixed $n \geq 1$ and $m \geq 0$, there exists $\hat{c} \in(0,1)$ such that every firm (incumbent or entrant) produces a positive output in equilibrium regardless of its realized cost, provided that $c \in(0, \hat{c})$.

Note that the first-order condition $\left(\mathrm{FOC}_{i}\right)$ defines implicitly the best reply in effort at firm $i$ as a function of the aggregate effort at the rival incumbent firms, $e_{-i}$, which is linear and downward sloping (see proof of Lemma 3(a) in Appendix A for more details). Managerial efforts and incentives are strategic substitutes. As a result, the symmetric equilibrium effort $e_{I}(m)$ is the unique equilibrium outcome. Now, in order to determine the equilibrium managerial effort, we evaluate the first-order condition $\left(\mathrm{FOC}_{i}\right)$ at a common effort level $e$. The marginal benefit of effort, denoted by $M B(e, m)$, is strictly decreasing in $e$ as shown by the downward sloping line in Figure 3. The upward sloping line, labeled $C^{\prime}(e)$, is the marginal incentive cost as a function of $e$. The intersection of $M B(e, m)$ and $C^{\prime}(e)$ yields the unique equilibrium managerial effort $e_{I}(m)$.

To find the upper bound $\hat{c}$ on the high marginal cost, note that the firm that produces the least in equilibrium is a high-cost entrant in a market in which all incumbents are low-cost. Let $q_{i}\left(c_{i}, e, m\right)$ denote the equilibrium output of an incumbent firm $i$ at marginal cost $c_{i}$ and a common effort level $e$ (among the incumbents), which is obtained from Lemma 2. Let $\hat{Q}_{I} \equiv \sum_{i \in I} q_{i}\left(0, e_{I}(m), m\right)$ be the aggregate incumbents output at equilibrium when all of them are low-cost. The upper bound $\hat{c}$ is implicitly defined by $q_{j}\left(c, e_{J}\left(\hat{Q}_{I}, m\right), \hat{Q}_{I}\right)=0$. For more details, see the proof of Proposition 1 in Appendix B.

\subsection{Competition and managerial incentives in the incumbent firms}

Our objective is to analyze how increased competition due to the entry of new firms into the market affects the provision of managerial incentives at the incumbent firms. The following proposition states our main result. 


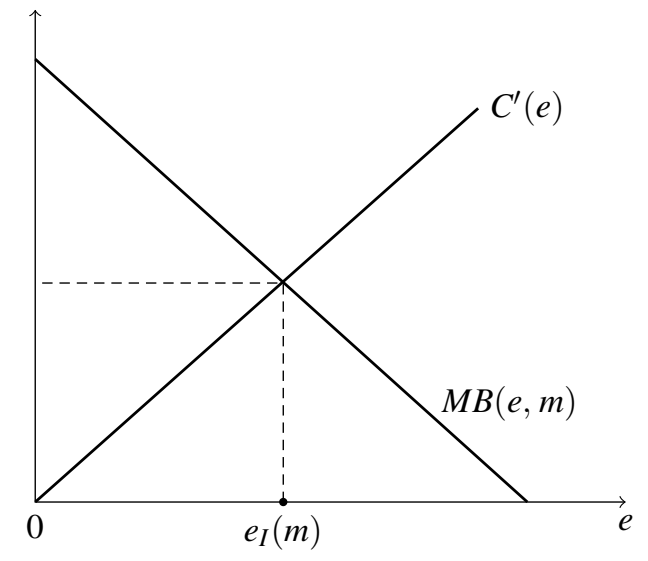

Figure 3: The equilibrium managerial effort in the incumbent firms.

Proposition 2 Let $m^{\prime}>m \geq 0$. Given any number of incumbents $n \geq 1$, entry of new firms induces each incumbent firm to elicit higher managerial effort, i.e., $e_{I}\left(m^{\prime}\right)>e_{I}(m)$, by providing stronger incentives, i.e., $w_{I}\left(m^{\prime}\right)>w_{I}(m)$, and higher compensation, i.e., $u_{I}\left(m^{\prime}\right)>u_{I}(m)$.

The above proposition implies two sorts of effects of competition on managerial incentives. The first one is an extensive margin effect. The equilibrium managerial effort, incentives, and compensations, are lower in the incumbent firms in the absence of any entrant firm. Even the entry of only one firm which sets quantity as a Stackelberg follower induces the incumbents to elicit higher managerial effort by offering stronger incentives and compensation. This is a consequence of the fact that both $e_{I}(m)$ and $w_{I}(m)$ are strictly increasing in $m$. The second is an intensive margin effect. As the competitive pressure intensifies, each incumbent firm elicits higher managerial effort and offers stronger incentives and compensations. On both grounds, Proposition 2 conforms to the 'managerial talent hypothesis' in the sense that greater compensation and stronger incentives imply that more talented managers would be lured into a more competitive environment.

The proof of Proposition 2 consists in showing that the equilibrium effort elicited by the incumbents, $e_{I}(m)$ given in (EI), is increasing in both the market size, $a(m)$, and the size of cost reduction, $\theta(m) c$, both of which are increasing functions of $m$. In order to see why entry of new firms induces the incumbents to elicit higher managerial effort, we analyze how an increased number of entrants affects the expected value of cost reduction and the expected marginal profitability of effort of incumbents, i.e., the two terms in the left-hand-side of $\left(\mathrm{FOC}_{i}\right)$ evaluated at a common effort level $e$ at the incumbent firms.

The effect of an increase in the number of entrants on the equilibrium output of both low- and highcost incumbents is shown in Figure 4. Entry of new firms induces the low-cost incumbents to produce more because both their market size and size of cost reduction increase. As $a(m)$ and $\theta(m)$ are both increasing functions of $m$, entry benefits the low-cost incumbents implying that $q_{i}(0, e, m)$ is strictly increasing in $m$. The same does not obtain for high-cost incumbents. The direction of the change in $q_{i}(c, e, m)$ following an increase in the number of entrants is a priori ambiguous because both $a(m)$ and $\theta(m)$ are increasing in $m$. From Figure 4, it is immediate to see that $q_{i}(c, e, m)$ is decreasing in $m$ if and only if $a^{\prime}(m)-\theta^{\prime}(m) c<0$, which turns out to be the case, i.e., the loss to the high-cost incumbents due to 


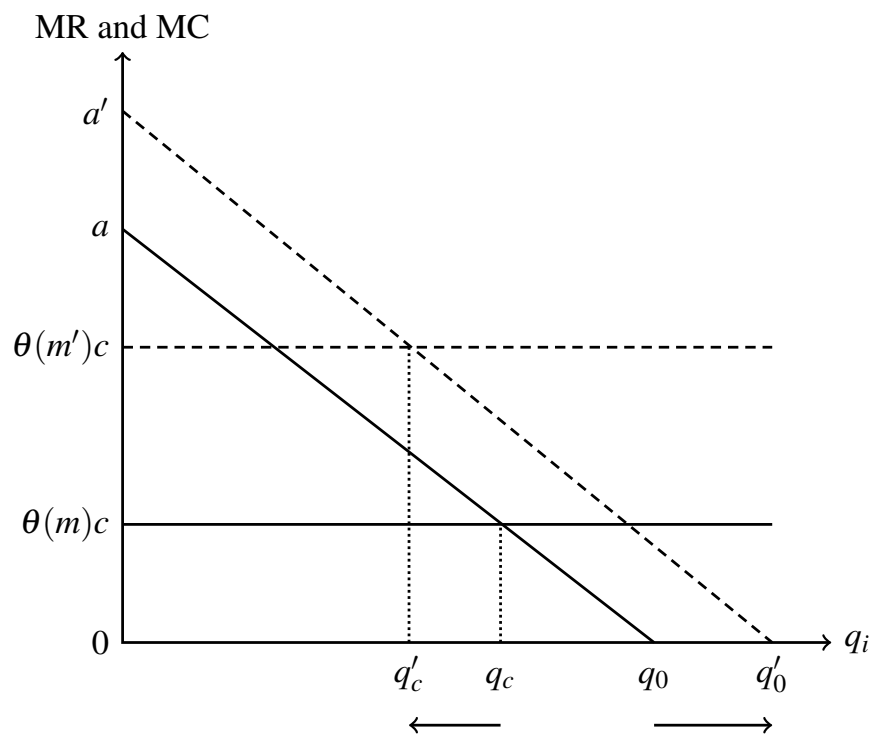

Figure 4: Effect of an increase in the number of entrants from $m$ to $m^{\prime}$ on the equilibrium outputs of low- and high-cost incumbents. Let $a \equiv a(m)-\mathbb{E} q_{-i}, a^{\prime} \equiv a\left(m^{\prime}\right)-\mathbb{E} q_{-i}, q_{c_{i}} \equiv q_{i}\left(c_{i}, e, m\right)$ and $q_{c_{i}}^{\prime} \equiv$ $q_{i}\left(c_{i}, e, m^{\prime}\right)$ for $c_{i} \in\{0, c\}$. Following an increase in $m, q_{0}$ increases to $q_{0}^{\prime}$, but $q_{c}$ decreases to $q_{c}^{\prime}$.

an increase in the size of cost reduction outweighs the gain from an increase in market size. ${ }^{4}$ Therefore, the entry of new firms strengthens the 'value-of-cost-reduction effect' because

$$
\frac{d \Delta \pi_{i}(e, m)}{d m}=2\left[q_{i}(0, e, m) \cdot \frac{d q_{i}(0, e, m)}{d m}-q_{i}(c, e, m) \cdot \frac{d q_{i}(c, e, m)}{d m}\right]>0,
$$

where $\Delta \pi_{i}(e, m)$ denotes the expected value of cost reduction of an incumbent firm at a common effort level $e$ (among the incumbents).

An increase in the number of entrants also affects the expected marginal profitability of effort. Following the above notation, let $\pi_{i}\left(c_{i}, e, m\right)$ denote the expected equilibrium profits of an incumbent firm, conditional on having realized marginal $\operatorname{cost} c_{i}$, at a common effort level $e$ (among the incumbents). Because the marginal productivity of effort is the same for every incumbent regardless of its realized cost at a common effort level $e$ (follows from Lemma 2), we may write the expected marginal profitability of effort at any incumbent firm $i$ as:

$$
\mathbb{E}\left[\frac{\partial \pi_{i}\left(c_{i}, e, m\right)}{\partial e_{i}}\right]=2\left[e q_{i}(0, e, m)+(1-e) q_{i}(c, e, m)\right] \cdot \frac{\partial q_{i}\left(c_{i}, e, m\right)}{\partial e_{i}},
$$

where the term in square braces is the expected optimal output of each incumbent. We show that $\mathbb{E}\left[\partial \pi_{i}\left(c_{i}, e, m\right) / \partial e_{i}\right]$ is an increasing function of $m$. First, note that the marginal productivity of effort is increasing in $m$, i.e., $\partial^{2} q_{i}\left(c_{i}, e, m\right) / \partial e_{i} \partial m>0$. Regardless of its cost realization, an incumbent's

\footnotetext{
${ }^{4}$ Note that

$$
a^{\prime}(m)-\theta^{\prime}(m) c=-\frac{c^{3} \theta(m)^{2} \kappa^{\prime}(m)}{2\left[1-C_{2} \kappa(m)\right]^{2}}<0
$$

because $\kappa^{\prime}(m)>0$. See Appendix B for details.
} 
optimal output is higher if its manager elicits more effort. As mentioned earlier, this is because the elicited effort pins down the beliefs of the rival firms over having attained lower marginal cost. But beyond this, the marginal productivity of effort is increasing in the number of entrants because it is proportional to the size of cost reduction, which is increasing in $\mathrm{m}$. Therefore, a sufficient condition for the 'marginal-profitability-of-effort effect' to be positive is that the expected incumbent output is increasing in the number of entrants. Showing this is not straightforward as only the output of low-cost incumbents is increasing in $m$. It turns out that the expected output is increasing in the number of entrants if the probability of accomplishing cost reduction is sufficiently high. At a common effort level $e$, this is equivalent to

$$
e>\frac{c^{2}}{2\left(4+c^{2}\right)} .
$$

The difficulty of showing the above inequality at the equilibrium effort level, $e=e_{I}(m)$, is that both sides are increasing functions of $c$. Becasue the upper bound $\hat{c}$ does not have a closed form solution (see Appendix B), it is simpler to verify that the condition holds numerically, by doing an extensive search in the parameter space. ${ }^{5}$

Given that both the 'value-of-cost-reduction effect' and the 'marginal-profitability-of-effort effect' are increasing in the number of entrants, the aggregate effect of an increase in the number of entrants on the marginal benefit of effort is positive. That is, at a common effort level $e$,

$$
\frac{d\left[\partial \Pi_{i}(e, m) / \partial e_{i}\right]}{d m}=\frac{d \Delta \pi_{i}(e, m)}{d m}+\frac{d \mathbb{E}\left[\partial \pi_{i}\left(c_{i}, e, m\right) / \partial e_{i}\right]}{d m}>0 .
$$

Therefore, at a common effort level $e$, an increase in $m$ shifts up the left-hand-side of $\left(\mathrm{FOC}_{i}\right)$ (the marginal effort benefit, i.e., the $M B(e, m)$ curve in Figure 3), and does not affect the right-hand-side (the marginal effort cost, i.e., the $C^{\prime}(e)$ curve in Figure 3$)$, causing the symmetric equilibrium effort in each incumbent firm to increase.

\subsection{Cross-sectional variation in the number of incumbents}

Up to this point, we have maintained the number of incumbents fixed. To emphasize the significance of Proposition 2, we analyze how equilibrium managerial effort varies with the number of incumbents, $n$ for a fixed number of entrants. This corresponds to comparing the managerial contracts offered at firms in two markets that face the same amount of competitive pressure (same number of entrants), but one of which is initially more competitive than the other (has more incumbents). Let $e_{I}(n, m) \equiv e_{I}(m)$, and $w_{I}(n, m) \equiv w_{I}(m)$, as defined in (EI), and $u_{I}(n, m) \equiv u_{I}(m)$, as defined in (2). (In this section we take the liberty of using notation defined previously, but change $m$ for $n$ to highlight the comparative statics in $n$.)

Proposition 3 Let $n^{\prime}>n \geq 1$. Given any fixed number of entrants $m \geq 0$, incumbents in more competitive markets, i.e., in ones with more incumbents, elicit lower managerial effort, i.e., $e_{I}\left(n^{\prime}, m\right)<e_{I}(n, m)$, by providing weaker incentives, i.e., $w_{I}\left(n^{\prime}, m\right)<w_{I}(n, m)$, and lower compensation, i.e., $u_{I}\left(n^{\prime}, m\right)<$ $u_{I}(n, m)$.

The marginal benefit of effort, the left-hand-side of $\left(\mathrm{FOC}_{i}\right)$, differs in two ways in markets that are initially more competitive. The first one is through the standard 'output channel'. More incumbents

\footnotetext{
${ }^{5}$ Despite the fact that we prove this claim numerically, the proof of Proposition 2 is fully analytical. For more details on this and the other claims below that we show numerically, see Appendix C.
} 
means greater aggregate production by rivals which implies that each firm optimally reduces its output at any realization of marginal cost as quantities are strategic substitutes. The expected value of cost reduction is lower as the effect of the number of incumbents on the optimal output level does not depend on the realized cost. That is, because $\partial q_{i}(0, e, n) / \partial n=\partial q_{i}(c, e, n) / \partial n<0$, one obtains

$$
\frac{d \Delta \pi_{i}(e, n)}{d n}=2\left[q_{i}(0, e, n)-q_{i}(c, e, n)\right] \cdot \frac{\partial q_{i}\left(c_{i}, e, n\right)}{\partial n}<0 .
$$

Notably, this 'value-of-cost-reduction effect' would work under the same logic if the realizations of marginal costs would have been public knowledge.

Due to the presence of privately realized marginal costs, a higher number of incumbents also changes the marginal benefit of managerial effort through the 'marginal-profitability-of-effort' effect. By eliciting a higher managerial effort, each incumbent $i$ induces its rivals to believe that it has attained a low marginal cost, and hence, the aggregate rival quantity is lower in expectation. This raises the expected market price, and hence, the expected profits of firm $i$, i.e., $\mathbb{E}\left[\partial \pi_{i}\left(c_{i}, e, n\right) / \partial e_{i}\right]>0$ at any realization of marginal cost. The marginal profitability of effort is greater if rivals believe that a given firm has attained cost reduction. In a more concentrated market (less firms) it is easier to influence rivals by affecting their beliefs, and hence, the marginal profitability of effort is increasing in the number of incumbents. In a market with many firms, by contrast, it is harder that more rivals are so influenced (as there are more firms). Thus, the marginal profitability of effort is decreasing in the number of incumbents in competitive markets. Formally,

$$
\frac{d \mathbb{E}\left[\partial \pi_{i}\left(c_{i}, e, n\right) / \partial e_{i}\right]}{d n}=-\frac{\theta(m) c(n-3)[a(m)-\theta(m) c(1-e)]}{(n+1)^{3}},
$$

which is strictly positive (negative) for $n<(>) 3$ as $c<\hat{c}<a(m) / \theta(m)$. (To see why this last inequality holds, note that the equilibrium output of a high-cost incumbent would be negative otherwise. See the proof of Proposition 1 in Appendix B for more details.). Thus, the effect of an increase in $n$ on the marginal profitability of effort may be positive or negative depending on the number of incumbents. Nonetheless, in either case, the aggregate effect of a higher number of incumbents on the marginal benefit of effort turns out to be always negative, i.e., $M B(e, n)$ in Figure 3 shifts down as $n$ increases with $C^{\prime}(e)$ remaining unaltered, and hence, $e_{I}(n, m)$ is decreasing in $n$. To see this formally, it suffices to note

$$
\frac{d M B(e, n)}{d n}=\frac{d \Delta \pi_{i}(e, n)}{d n}+\frac{d \mathbb{E}\left[\partial \pi_{i}\left(c_{i}, e, n\right) / \partial e_{i}\right]}{d n}=-\frac{2 \theta(m) c(n-1)[a(m)-\theta(m) c(1-e)]}{(n+1)^{3}}<0 .
$$

The crucial difference between varying the number of entrants and incumbents, is that the entry of new firms affects the incumbents' output decision by altering their effective market size and the size of cost reduction. If there are more incumbents to start with, this alters directly the number of firms incumbents are competing against, and leaves the market size and the size of cost reduction unaffected. The juxtaposition of propositions 2 and 3 highlights the driving force underlying our main result. The fact that incumbents find it optimal to elicit higher managerial effort by offering steeper incentive contracts when they foresee the entry of new firms to the market, is due to incumbents being able to affect the entrants' output decisions by committing to an output level before they start producing.

\subsection{Managerial incentives in simultaneous oligopoly}

The objective of this section is to analyze the effect of entry on managerial efforts and incentives in the incumbent firms when the $m$ entrant firms are allowed set quantities simultaneously along with the 
$n$ incumbents. The simultaneous setting is nothing but a Cournot market with $n+m$ symmetric firms and privately realized marginal costs $\left(c_{1}, \ldots, c_{n}, c_{1}, \ldots, c_{m}\right)$. The equilibrium managerial effort in each firm (incumbent or entrant) can be obtained directly from the expression (EI) as follows. As the entrants are treated equally as the incumbents, remove the entrants by setting $m=0$, and replace the number of incumbents, $n$, by $n+m$. In this case, $a(m)=\theta(m)=1$.

Let the symmetric equilibrium managerial effort and incentives in each firm (incumbent or entrant) be denoted by $e^{\operatorname{sim}}(n+m)$ and $w^{\text {sim }}(n+m)$, respectively, and note that a manager's equilibrium utility is given by:

$$
u^{\operatorname{sim}}(n+m) \equiv e^{\operatorname{sim}}(n+m) w^{\operatorname{sim}}(n+m)-\frac{1}{2}\left(e^{\operatorname{sim}}(n+m)\right)^{2}=\frac{1}{2}\left(w^{\operatorname{sim}}(n+m)\right)^{2} .
$$

The effect of an entrant in an incumbent's optimal managerial effort and contract in this setting is analogous to considering a market that has one more incumbent (in this setting, entrants and incumbents are symmetric). Hence, we obtain the following corollary directly from Proposition 3.

Corollary 1 Let $m^{\prime}>m \geq 0$. In a simultaneous quantity-setting oligopoly in which $m$ entrants set quantities and managerial contracts along $n \geq 1$ incumbents, entry of new firms implies that each incumbent elicits lower managerial effort, i.e., $e^{\text {sim }}\left(n+m^{\prime}\right)<e^{s i m}(n+m)$, by providing weaker incentives to its manager, i.e., $w^{\text {sim }}\left(n+m^{\prime}\right)<w^{\text {sim }}(n+m)$, and lower compensation, i.e., $u^{\text {sim }}\left(n+m^{\prime}\right)<u^{\text {sim }}(n+m)$.

The result in Corollary 1 is not new in the literature (see Martin, 1993; Hermalin, 1994; Golan et al., 2015). The intuition behind it goes in the same line as the one underlying Proposition 3. The entrants affect the marginal benefit of effort of the incumbents through the 'value-of-cost-reduction' and 'marginal-profitability-of-effort' effects. As noted in section 4.5 above, in this case the entrants imply a lower expected value of cost reduction for the incumbents, and also a lower expected marginal profit of effort as long as the market is already sufficiently competitive or, equivalently, the number of entrants is sufficiently high, i.e., as long as $n+m>3$. In contrast to when the entrants act as followers by setting contracts and quantities after the incumbents, in this case, the entrants do not change the market size or the size of cost reduction for the incumbents. Notably, as highlighted in the extant literature, the result in Corollary 1 does not depend on marginal costs being privately realized. On the contrary, we show that the negative effect of competition on managerial incentives in this setting is reinforced with privately realized marginal costs if the market is sufficiently competitive.

\section{Testable implications}

\subsection{Nature of industry competition and time to build production capacity}

A key insight of our stylized model is the juxtaposition of Proposition 2 with Corollary 1 . If entrants set quantities sequentially, incumbent firms offer stronger managerial incentives as the number of entrants grows, whereas the opposite is obtained if they set quantities simultaneously, along with the incumbents. How can one relate these contrasting results to the nature of competition that prevails in various industries?

In a seminal contribution to the literature on oligopolistic competition, Kreps and Scheinkman (1983) analyze a two-stage game where firms simultaneously choose their production capacities in the first stage, 
and compete in prices in the stage that follows. They show, under very general conditions, that simultaneous capacity pre-commitment followed by price competition yields the Cournot outcome. By contrast, Allen et al. (2000) show that when firms choose capacities sequentially, i.e., the entrant firms choose capacities after observing the capacities set by the incumbents, and then the firms compete in prices, the subgame perfect equilibrium yields the Stackelberg outcome. An entrant firm cannot instantaneously adjust its capacity as it requires time to build, which is the crux of Allen et al.'s (2000) analysis. Thus, the Cournot outcome, which is the result of simultaneous capacity pre-commitment both by the incumbents and entrants (followed by price competition), is based on a no-time-to-build assumption. This disparity in the time taken to build production capacity implies the following.

Implication 1 In an industry where production capacity requires 'time to build', the incumbent firms offer higher managerial compensation and stronger incentive pay following an increase in the market competition induced by the entry of new firms. By contrast, if the production capacity can be adjusted instantaneously, entry of new firms implies that incumbents would provide lower compensation and weaker incentives to their managers following entry.

Production capacities can be built almost instantaneously due to the presence of low sunk costs in industries, e.g. services and technology. Therefore, our results imply that more competition may be detrimental to managerial performance in such industries. On the other hand, in industries where capacity requires time to build, such as the airline or banking industries, more competition in the form of firm entry forces incumbents to improve their managerial performance by offering steeper incentive contracts.

It is worth emphasizing that Implication 1 applies both at the extensive and the intensive margins. When there is (no) time to build production capacity, both (i) firm entry increases (decreases) incumbents managerial effort and managerial pay, i.e., at the extensive margin, and (ii) a higher number of entrants increases (decreases) each incumbent's managerial effort and incentive pay by a larger magnitude, i.e., at the intensive margin. Figure 5 depicts the juxtaposition of Proposition 2 with Corollary 1. From (EI) it follows that $e_{I}(n, 0)=e^{\operatorname{sim}}(n+0)$. In the absence of any entrant firm $(m=0)$, the equilibrium efforts coincide because it makes no difference whether entrants set managerial contracts and quantities after or along with the incumbents. Because $e_{I}(n, m)$ is strictly increasing in $m$, and $e^{\operatorname{sim}}(n+m)$ is strictly decreasing in $m$, the equilibrium managerial incentives are not only higher when time is required to build capacity, but also their differences magnify as the number of entrants grows. Therefore, even a monopolist incumbent $(n=1)$ would respond more aggressively to an increase in the threat of competition under time-to-build-capacity, whereas she would provide weaker managerial incentives if the time to build capacity were negligible.

\subsection{Equilibrium product market prices and profits}

We focus on the effect that entry of new firms has on the equilibrium expected market price and the incumbents' expected market profits. Rather than dealing with the analytical complexity of these two equilibrium objects, we simplify the analysis by analyzing them numerically. We use a granular grid of the model's parameters to validate Implications 2 and 3 below. ${ }^{6}$

\footnotetext{
${ }^{6}$ For more details on the numeric implementation of the model, see Appendix C.
} 


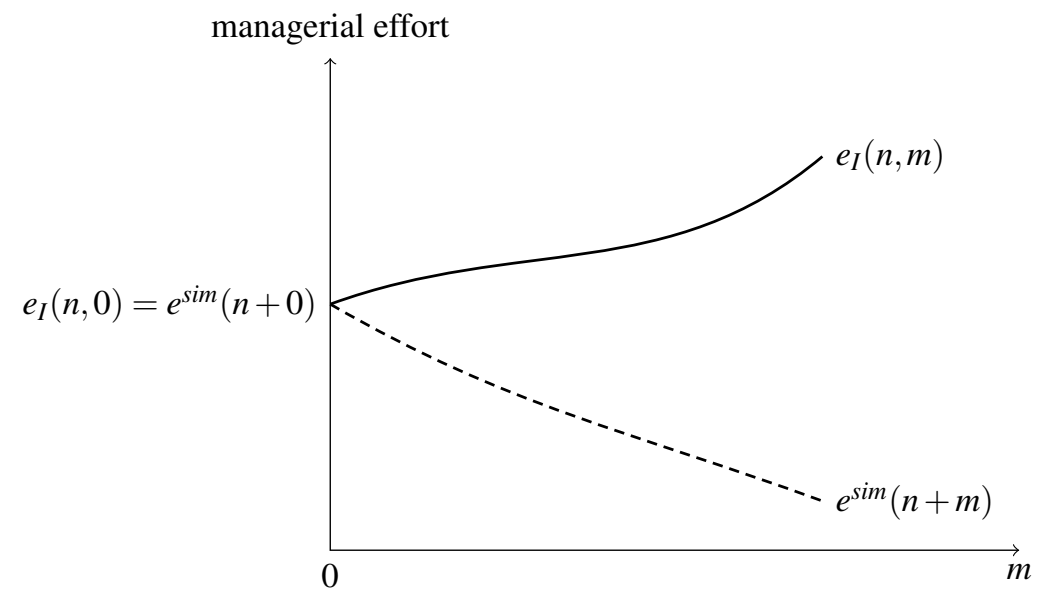

Figure 5: Equilibrium managerial effort as a function of the number of entrants $m$ under simultaneous and sequential quantity-setting oligopolies for a given number of incumbents $n$.

Implication 2 Under both market structures, simultaneous and sequential oligopolies, the equilibrium expected market price decreases with the number of entrants. However, it is higher when the entrants set quantities simultaneously along with the incumbents than when they set them after, as Stackelberg followers.

Implication 2 encapsulates two observations. First, the expected market price is decreasing in the number of entrants, whatever may be the nature of competition, simultaneous or sequential (or the time to build production capacity). This is not surprising because more firms implies a higher aggregate output. However, the price decreases more rapidly in the number of entrants when they set quantities after the incumbents. This is because in the simultaneous case, all firms are symmetric, and hence, the expected equilibrium outputs of the incumbents and entrants are equal. By contrast, in the sequential case, a higher output by an incumbent translates into a lower output by all the entrants, both directly through diminishing the price and indirectly through the reduction in the managerial incentives of every entrant firm. Second, whatever may be the number of incumbents, the expected market price is lower when entrants produce sequentially. These two observations can be appreciated in Figure 6, which plots the equilibrium expected market price as a function of $m$ and $n$, for a given value of $c$. Even though the plots are for a fixed value of $c$, we show numerically that the same holds over the entire parameter space. The comparison of price levels under the two market structures suggests that the sequential quantitysetting oligopoly represents more intense competition than the simultaneous quantity-setting oligopoly. Or equivalently, in the lines of Implication 1, that the time to build capacity in an industry may be reflected in the way that firm entry affects the market price.

Implication 3 The equilibrium expected market profits of each incumbent decrease with the number of entrants when these set quantities along with the incumbents simultaneously. By contrast, the equilibrium expected market profits of each incumbent are increasing when the entrants set quantities afterwards, as Stackelberg followers.

According to Implication 3, the expected market profits behave qualitatively similar to the managerial 

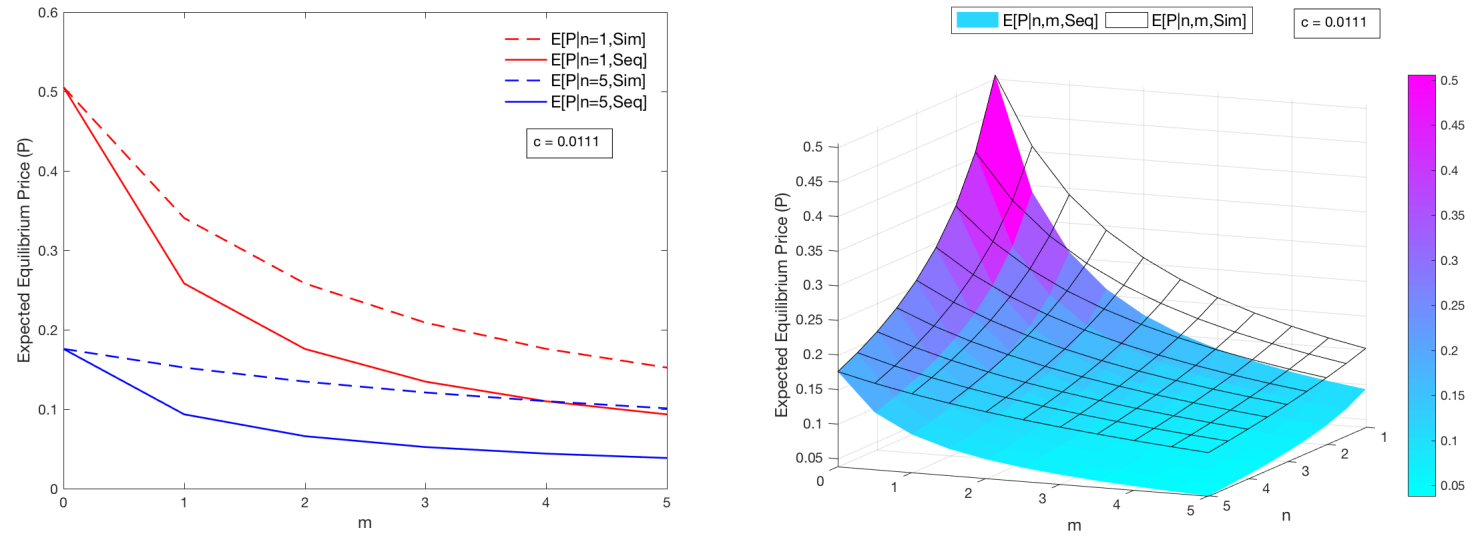

Figure 6: Equilibrium expected price in simultaneous and sequential oligopolies

effort in equilibrium (cf. Proposition 2): the higher the number of entrants, the higher are the expected market profits of the incumbents. This result goes in line with our finding in the previous section; namely, with the fact that the incumbents equilibrium expected output is increasing in the number of entrants. By strengthening managerial incentives, incumbents counteract the effect that the entry of new firms has on market price. Interestingly, the size of the relative change in profits is small relative to that undergone when entrants set quantities along with the incumbents simultaneously. This can be seen in Figure 7. Although equilibrium profits are clearly decreasing in the number of firms when entrants set quantities simultaneously, they increase only slightly when entrants are Stackelberg followers. Indeed, incumbent profits seem to be flat graphically. Nonetheless, we show numerically that they are not; they are strictly increasing in the number of entrants over the entire parameter space.
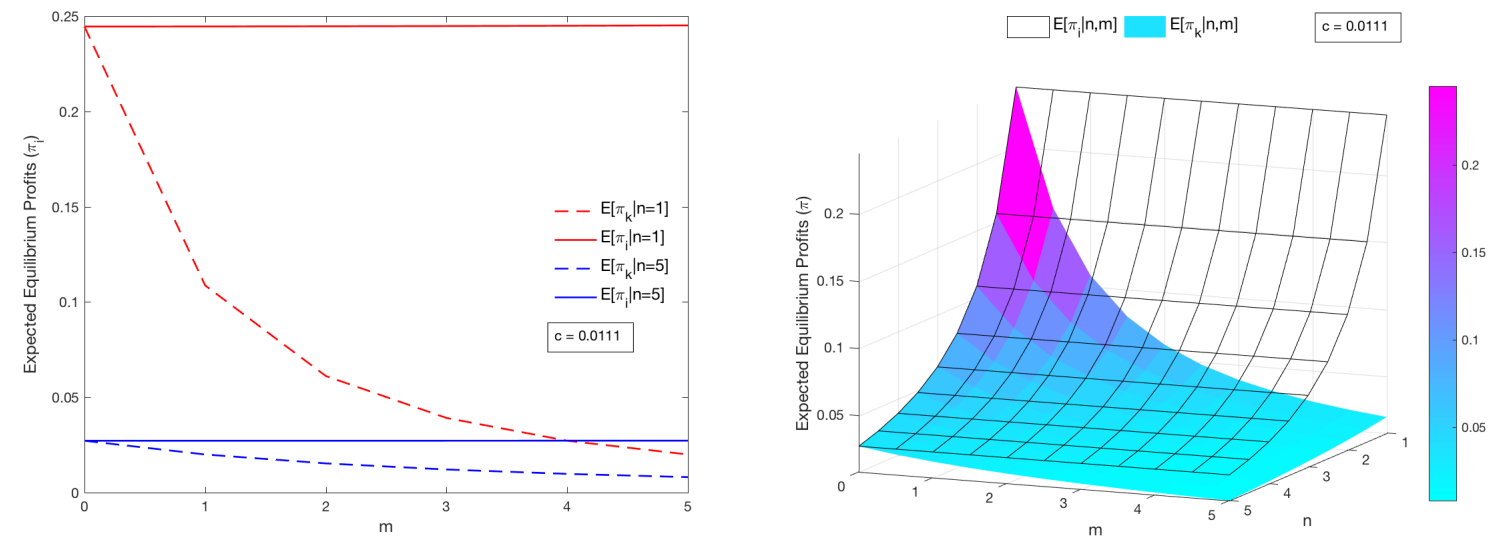

Figure 7: Equilibrium expected product market profits of each incumbent in the simultaneous and sequential oligopolies 


\section{Conclusion}

Motivated by empirical evidence, in this paper we investigate how firms adjust executive compensation packages following deregulation policies that intensify product market competition by allowing the entry of new firms. Using a standard incentive contracting model under quantity-setting oligopoly, we show that incumbent firms find it optimal to elicit higher managerial effort by offering stronger incentive contracts when they foresee entry of new firms into the product market. Our model allows us to tease out in detail the channels through which product market competition affects managerial incentives in a setting with firm entry. In our model, the key features that link the number of entrants with an incumbent's contracting problem are the market size and the size of cost reduction, both of which affect the marginal benefit of effort, through the expected value of cost reduction, and the expected marginal profitability of effort. By showing that firm entry increases both the market size and the size of cost reduction for incumbents, and analyzing, in turn, how these two affect the expected value of cost reduction, and the expected marginal profitability of effort, we show that incumbents find it optimal to offer stronger managerial incentives when new firms enter the market. Furthermore, we also show that the magnitude in which incumbents strengthen managerial incentives is increasing in the number of entrants: a higher competitive pressure triggers a starker reaction by the incumbents.

Beyond conforming to the empirical regularities, our model also sheds light on how the nature of competition in product market affects managerial incentives. Namely, we explore the connection between the time to build production capacity in an industry and the effect that product market competition has on managerial incentives. We find that firm entry increases the pay-performance sensitivity of managerial contracts in markets in which production capacity takes time to build. In other words, the key driver of our result is that entrants act as Stackelberg followers in the product market by taking the aggregate output of incumbents as given. In the opposite case in which production capacity may be obtained instantaneously, i.e., entrants are symmetric to incumbents and set contracts and output simultaneously along with them, the association is negative: incumbents find it optimal to offer weaker managerial incentives as more firms enter the market. Notably, this setting is equivalent to comparing a market that is already more competitive (with more incumbents in the first place). Hence, our model relates to the previous literature by replicating the known result that firms in Cournot markets with more firms offer weaker incentives. However, we show that this case is reinforced regardless of the number of entrants. Incumbents in markets that were already more competitive offer weaker managerial incentives even if there is competitive pressure, as long as it is constant (same number of entrants). 


\section{Appendices}

\section{A The base model}

The subgames played by the entrants and the incumbents have the same underlying structure. In this section, we analyze a more general version of the simultaneous quantity competition model with a fixed number $N$ of firms, called the base model, which yields most of the results in Section 4 . Let $K$ be the set of firms, with $|K|=N \geq 1$, and index firms with $k$. Let $P=A-B Q$ be the inverse market demand with $A, B>0$. The marginal cost of a representative firm $k$ is given by $c_{k}$, with $c_{k} \in\{0, c\}$ with $c \in(0, \bar{c})$. The upper bound $\bar{c}$ is such that all firms produce a positive output in equilibrium regardless of their realized marginal costs. We will prove that such bound exists. Define by $a \equiv A / B$ the market size of each firm, and $\theta \equiv 1 / B$ so that $\theta c$ represents the size of cost reduction of each firm. The following lemma describes the main results of the base model.

Lemma 3 Consider the base model.

(a) The equilibrium effort is symmetric and unique across all firms. It is given by:

$$
e(N)=\frac{\theta c\left[8 a N+\theta c\left(N^{2}-6 N+1\right)\right]}{2\left[4(N+1)^{2}+\theta^{2} c^{2}(N-1)^{2}\right]} .
$$

Moreover, the second order condition associated with the individual firm maximization problem in a Bayesian Cournot equilibrium is satisfied for every firm if all of them produce a positive quantity in equilibrium.

(b) If $a$ and $\theta$ are independent of $c$, then there is $\bar{c} \in(0, a / \theta)$ such that, if $c \in(0, \bar{c})$, every firm produces a strictly positive quantity of output and elicits strictly positive level of managerial effort in a symmetric equilibrium, regardless of its realized marginal cost.

(c) If $c \in(0, \bar{c})$, the equilibrium effort in (EC) is decreasing in the number of firms, and increasing in the market size and the size of cost reduction. That is, for every $N \geq 1$,

$$
\frac{d e(N)}{d N}<0, \quad \frac{d e(N)}{d a}>0, \quad \text { and } \quad \frac{d e(N)}{d(\theta c)}>0 .
$$

Proof

(a) Once all the contracts are observed and marginal costs are privately realized, each firm $k$ solves

$$
\max _{q_{k}} q_{k}\left[A-B\left(q_{k}+\mathbb{E} q_{-k}\right)-c_{k}\right] .
$$

The first-order condition of the above maximization problem is given by:

$$
\begin{aligned}
& A-2 B q_{k}-B \mathbb{E} q_{-k}-c_{k}=0 \\
\Longleftrightarrow & 2 B q_{k}=A-c_{k}-B \mathbb{E} q_{-k} \\
\Longleftrightarrow & q_{k}\left(c_{k}, \mathbb{E} q_{-k}\right)=\frac{A-c_{k}}{2 B}-\frac{1}{2} \mathbb{E} q_{-k} .
\end{aligned}
$$


Taking expectation in the above equation, we get

$$
\mathbb{E} q_{k}=\frac{A-\mathbb{E} c_{k}}{2 B}-\frac{1}{2} \mathbb{E} q_{-k}=\frac{A-c\left(1-e_{k}\right)}{2 B}-\frac{1}{2} \mathbb{E} q_{-k} .
$$

Summing the above over $k$ we get

$$
\begin{aligned}
& \sum_{k=1}^{N} \mathbb{E} q_{k}=\frac{N(A-c)}{2 B}+\frac{c}{2 B} \sum_{k=1}^{N} e_{k}-\frac{N-1}{2} \sum_{k=1}^{N} \mathbb{E} q_{k} \\
& \Longleftrightarrow \sum_{k=1}^{N} \mathbb{E} q_{k}=\frac{1}{B(N+1)}\left[N(A-c)+c \sum_{k=1}^{N} e_{k}\right] .
\end{aligned}
$$

On the other hand, (4) can be written as

$$
\begin{aligned}
& \mathbb{E} q_{k}=\frac{A-c\left(1-e_{k}\right)}{2 B}-\frac{1}{2}\left(\sum_{l=1}^{N} \mathbb{E} q_{l}-\mathbb{E} q_{k}\right) \\
\Longleftrightarrow & \frac{1}{2} \mathbb{E} q_{k}=\frac{A-c\left(1-e_{k}\right)}{2 B}-\frac{1}{2 B(N+1)} \cdot\left[N(A-c)+c \sum_{k=1}^{N} e_{k}\right] \\
\Longleftrightarrow & \mathbb{E} q_{k}=\frac{A-c+c\left(N e_{k}-e_{-k}\right)}{B(N+1)},
\end{aligned}
$$

where $e_{-k}=\sum_{l \in K \backslash\{k\}} e_{l}$. Thus, using the fact that $\mathbb{E} q_{-k}=\sum_{l=1}^{N} \mathbb{E} q_{l}-\mathbb{E} q_{k}$, and substituting for $\sum_{l=1}^{N} \mathbb{E} q_{l}$ and $\mathbb{E} q_{k}$ from (5) and (6), from (3) we obtain the quantity and profit of each firm in the Bayesian Cournot equilibrium, which are respectively given by:

$$
\begin{aligned}
q_{k}\left(c_{k}, e_{k}, e_{-k}\right) & =\frac{2 A-(N+1) c_{k}+(N-1) c\left(1+e_{k}\right)-2 c e_{-k}}{2 B(N+1)} \\
& =\frac{2 a-(N+1) \theta c_{k}+(N-1) \theta c\left(1+e_{k}\right)-2 \theta c e_{-k}}{2(N+1)} \\
\pi_{k}\left(c_{k}, e_{k}, e_{-k}\right) & =\left(\frac{2 a-(N+1) \theta c_{k}+(N-1) \theta c\left(1+e_{k}\right)-2 \theta c e_{-k}}{2(N+1)}\right)^{2}
\end{aligned}
$$

The expression in (7) is obtained by using the facts that $a \equiv A / B$ and $\theta \equiv 1 / B$. At date 1 , each firm $k$ chooses the optimal managerial incentives to solve

$$
\max _{e_{k}} e_{k} \pi_{k}\left(0, e_{k}, e_{-k}\right)+\left(1-e_{k}\right) \pi_{k}\left(c, e_{k}, e_{-k}\right)-e_{k}^{2} .
$$

The expected value of cost reduction, $\Delta \pi_{k}\left(e_{k}, e_{-k}\right):=\pi_{k}\left(0, e_{k}, e_{-k}\right)-\pi_{k}\left(c, e_{k}, e_{-k}\right)$ of firm $k$ is given by:

$$
\Delta \pi_{k}\left(e_{k}, e_{-k}\right)=\frac{\theta c\left[4 a+\theta c(N-3)+2 \theta c(N-1) e_{k}-4 \theta c e_{-k}\right]}{4(N+1)} .
$$

Also, note that

$$
e_{k} \cdot \frac{\partial \pi_{k}\left(0, e_{k}, e_{-k}\right)}{\partial e_{k}}+\left(1-e_{k}\right) \cdot \frac{\partial \pi_{k}\left(c, e_{k}, e_{-k}\right)}{\partial e_{k}}=\frac{\theta c(N-1)\left[a-\theta c+\theta c\left(N e_{k}-e_{-k}\right)\right]}{(N+1)^{2}} .
$$


Using the expressions (10) and (11), the first-order condition of the maximization problem in (9) is given by:

$$
\begin{aligned}
& \Delta \pi_{k}\left(e_{k}, e_{-k}\right)+e_{k} \cdot \frac{\partial \pi_{k}\left(0, e_{k}, e_{-k}\right)}{\partial e_{k}}+\left(1-e_{k}\right) \cdot \frac{\partial \pi_{k}\left(c, e_{k}, e_{-k}\right)}{\partial e_{k}}=2 e_{k} \\
& \frac{\theta c\left[8 a N+\theta c\left(N^{2}-6 N+1\right)+6 \theta c\left(N^{2}-1\right) e_{k}-8 \theta c N e_{-k}\right]}{4(N+1)^{2}}=2 e_{k} . \quad\left(\mathrm{FOC}_{k}^{\prime}\right)
\end{aligned}
$$

Condition $\left(\mathrm{FOC}_{k}^{\prime}\right)$ implicitly defines the best response (in effort) $e_{k}\left(e_{-k}\right)$ of the manager at firm $k$, which is given by:

$$
e_{k}\left(e_{-k}\right)=\underbrace{\frac{\theta c\left[8 a N+\theta c\left(N^{2}-6 N+1\right)\right.}{2\left[4(N+1)^{2}-\theta^{2} c^{2}(3 N+1)(N-1)\right]}}_{\alpha(N, a, \theta c)}-\underbrace{\left(\frac{4 \theta^{2} c^{2} N}{4(N+1)^{2}-\theta^{2} c^{2}(3 N+1)(N-1)}\right)}_{\beta(N, a, \theta c)} e_{-k}
$$

The best response is linear $e_{k}\left(e_{-k}\right)=\alpha-\beta e_{-k}$, where $\alpha \equiv \alpha(N, a, \theta c)$ and $\beta \equiv \beta(N, a, \theta c)$ are constants. Let $e_{K}=\sum_{k \in K} e_{k}$. Summing over all $k$, in equilibrium: $e_{K}=N \alpha-\beta \sum_{k} e_{-k}$. Thus,

$$
e_{K}=\frac{N \alpha}{1+\beta(N-1)}
$$

where we use $\sum_{k} e_{-k}=(N-1) e_{K}$. As $e_{K}=e_{-k}+e_{k}$, the equilibrium effort is given by:

$$
e_{k}=\frac{\alpha}{1+\beta(N-1)} \text {. }
$$

Replacing the values for the constants $\alpha$ and $\beta$ yields the equilibrium effort given in (EC). In other words, effort choices are strategic substitutes, and there exists a unique symmetric equilibrium.

Next, we show that the second order condition is satisfied for every firm if all of them produce a positive output in equilibrium. Note that the second-order condition of firm $k$ 's maximization problem (9) is given by:

$$
\begin{aligned}
& 2\left(\frac{\partial \Delta \pi_{k}}{\partial e_{k}}\right)+e_{k} \cdot \frac{\partial^{2} \Delta \pi_{k}}{\partial e_{k}^{2}}+\frac{\partial^{2} \pi_{k}(c, \cdot)}{\partial e_{k}^{2}}-2 \leq 0 \\
\Longleftrightarrow & \frac{\theta^{2} c^{2}(N-1)}{(N+1)}+\frac{\theta^{2} c^{2}(N-1)^{2}}{2(N+1)^{2}}-2 \leq 0 .
\end{aligned}
$$

Note that $\left(\mathrm{SOC}_{k}\right)$ holds if $N=1$, and it is equivalent to

$$
\theta c \leq \frac{2(N+1)}{\sqrt{(N-1)(3 N+1)}} \text { for } N \geq 2 .
$$

Let $q_{k}\left(c_{k}\right)$ be the equilibrium output of a firm with realized marginal $\operatorname{cost} c_{k}$, i.e., $q_{k}\left(c_{k}\right)=q_{k}\left(c_{k}, e_{k}, e_{-k}\right)$ with $e_{k}=e(N)$ for every $k \in K$. From (7), it follows that $q_{k}(c)=q_{k}(0)-\theta c / 2$, so $q_{k}(c)>0$ for all $k$ implies

$$
\theta c<\frac{2}{N} \sum_{k} q_{k}(0)
$$

The upper bound on $\theta c$ in (12) is lower than the one in $\left(\mathrm{SOC}_{k}^{\prime}\right)$ as, by construction, $\sum_{k} q_{k}(0)<1$ (otherwise the equilibrium price would be negative), and $N(N+1) / \sqrt{(N-1)(3 N+1)}>1$ for each $N \geq 2$. 
(b) We prove the existence of $\bar{c} \in(0, a / \theta)$ such that $c \in(0, \bar{c})$ implies $q_{k}\left(c_{k}\right)>0$ in equilibrium for every $k \in K$ and $c_{k} \in\{0, c\}$. Fix $N \geq 1$. Write $e(N, c) \equiv e(N)$. From (7), see that the symmetric equilibrium production of a high-cost firm is lower than that of a low-cost firm and satisfies:

$$
q_{k}(c)=\frac{2(a-\theta c)-\theta c(N-1) e(N, c)}{2(N+1)}>0 \Longleftrightarrow f(N, c) \equiv \frac{2(a-\theta c)}{\theta c(N-1)}-e(N, c)>0 .
$$

Note that

$$
\begin{aligned}
& \lim _{c \rightarrow 0} f(N, c)=\infty, \\
& f(N, a / \theta)=0-\frac{a^{2}(N+1)^{2}}{2\left[4(N+1)^{2}+a^{2}(N-1)^{2}\right]}<0 .
\end{aligned}
$$

Therefore, by Intermediate Value Theorem, there is $c_{0} \in(0, a / \theta)$ such that $f\left(N, c_{0}\right)=0$. If $c_{0}$ is unique, then take $\bar{c}=c_{0}$. Otherwise, take $\bar{c}=\min \left\{c_{0}\right\}$. Next, we prove that $e(N, c)>0$ for $c \in(0, \bar{c})$, which is equivalent to the following:

$$
8 a N+\theta c\left(N^{2}-6 N+1\right)>0 .
$$

Given that $a>\theta c$, we have

$$
8 a N+\theta c\left(N^{2}-6 N+1\right)>8 \theta c+\theta c\left(N^{2}-6 N+1\right)=\theta c(N+1)^{2}>0,
$$

which proves (14) for all $N \geq 1$.

(c) Fix $N \geq 1$. Differentiating (EC) with respect to $N$ we obtain

$$
\frac{\partial e(N)}{\partial N}=-\frac{2 \theta c\left(N^{2}-1\right)\left[8 b^{2}(a-\theta c)+\theta^{2} c^{2}(2 a-\theta c)\right.}{\left[4 b^{2}(N+1)^{2}+\theta^{2} c^{2}(N-1)^{2}\right]^{2}} .
$$

The above expression is negative for $a>\theta c$. Next,

$$
\frac{\partial e(N)}{\partial a}=\frac{8 \theta c N}{2\left[4 b^{2}(N+1)^{2}+\theta^{2} c^{2}(N-1)^{2}\right]}>0 .
$$

Finally, use the fact that $e(N)>0$ to verify $\partial e(N) / \partial(\theta c)>0$. Note that

$$
\frac{\partial e(N)}{\partial(\theta c)}>0 \quad \Longleftrightarrow \quad e(N)<\frac{4 a N+\theta c\left(N^{2}-6 N+1\right)}{2 \theta c(N-1)^{2}} .
$$

Because of the interior solution condition in (13), it suffices to show

$$
\begin{aligned}
& \frac{2(a-\theta c)}{\theta c(N-1)}<\frac{4 a N+\theta c\left(N^{2}-6 N+1\right)}{2 \theta c(N-1)^{2}} \\
\Longleftrightarrow & 4(a-\theta c)+\theta c(N-1)^{2}>0 .
\end{aligned}
$$

The last inequality holds as $a>\theta c$.

This completes the proof of Lemma 3. 


\section{B Proofs}

Most of the following proofs follow directly from the analysis of the base model, see Lemma 3 in Appendix A.

\section{Proof of Lemma 1}

The proof directly follows from Lemma 3(a) with $A=1-Q_{I}, B=1$, and $N=m$.

\section{Proof of Lemma 2}

The proof directly follows from the proof of Lemma 3 with $A=A(m), B=B(m)$, and $N=n$; see equations (7) and (8).

\section{Proof of Proposition 1}

The maximization problem of each incumbent $i$ is given by:

$$
\begin{aligned}
& \max _{q_{i}} q_{i}\left(1-q_{i}-\mathbb{E} q_{-i}-Q_{J}\left(q_{i}+\mathbb{E} q_{-i}\right)-c_{i}\right) \\
\Longleftrightarrow & \max _{q_{i}} q_{i}[\underbrace{\left(1-C_{1} \kappa(m)\right)}_{A(m)}-\underbrace{\left(1-C_{2} \kappa(m)\right)}_{B(m)}\left(q_{i}+\mathbb{E} q_{-i}\right)-c_{i}]
\end{aligned}
$$

Therefore, setting $a \equiv a(m)=\frac{A(m)}{B(m)}, \theta \equiv \theta(m)=1 / B(m)$ and $N=n$ it follows from Lemma 3(a) that

$$
e(m)=\frac{\theta(m) c\left[8 a(m) n+\theta(m) c\left(n^{2}-6 n+1\right)\right]}{2\left[4(n+1)^{2}+\{\theta(m) c\}^{2}(n-1)^{2}\right]} .
$$

Recall that the subgame played by the entrants is equivalent to the base model with $B=1, a=A / B=$ $1-Q_{I}$ and $\theta=1 / B=1$. We cannot apply the bound in Lemma 3(b) directly as $a$ depends on $c\left(Q_{I}\right.$ is an equilibrium object that depends on the model's parameters). Obtain the equilibrium output of a high-cost entrant by replacing $a=1-Q_{I}$ and $\theta=1$ in (7):

$$
q_{j}\left(c, Q_{I}\right)=\frac{2\left(1-Q_{I}-c\right)-c(m-1) e_{J}\left(m, Q_{I}\right)}{2(m+1)},
$$

where $e_{J}\left(m, Q_{I}\right)$ is the optimal effort of the entrants given in (EE). Because low-cost entrants produce more than high-cost ones in equilibrium, the interior solution condition is equivalent to $q_{j}\left(c, Q_{I}^{*}\right)>0$, where $Q_{I}^{*}$ is the total output of the incumbents in the symmetric equilibrium. Note that $q_{j}\left(c, Q_{I}\right)$ is decreasing in $Q_{I}$ as

$$
\begin{aligned}
& \frac{\partial q_{j}\left(c, Q_{I}\right)}{\partial Q_{I}}<0 \\
\Longleftrightarrow & 2-\frac{4 c^{2} m(m-1)}{4(m+1)^{2}+c^{2}(m-1)^{2}}>0 \\
\Longleftrightarrow & m^{2}\left(4-c^{2}\right)+m\left(8-c^{2}\right)+4+c^{2}>0 .
\end{aligned}
$$


Hence, a high-cost entrant produces the least when all incumbents have low costs. Let $q_{i}(0)$ be the optimal output of a low-cost incumbent, so the interior solution for each entrant $j$ requires $q_{j}\left(c, \sum_{i \in I} q_{i}(0)\right)>$ 0 . By (15), this is equivalent to

$$
\sum_{i} q_{i}(0)<1-c-\frac{c(m-1) \cdot e_{J}\left(\sum_{i} q_{i}(0)\right)}{2} .
$$

From (7), the equilibrium output of a low-cost incumbent is given by:

$$
q_{i}(0)=\frac{2 a(m)+\theta(m) c(n-1)(1-e(m))}{2(n+1)} .
$$

Because $\kappa(m) \rightarrow m /[4(m+1)], a(m) \rightarrow 1, \theta(m) \rightarrow m+1$, and $e(m) \rightarrow 0$, as $c \rightarrow 0$, we have

$$
\lim _{c \rightarrow 0} \sum_{i} q_{i}(0)=\frac{n}{n+1}<1=\lim _{c \rightarrow 0} 1-c-\frac{c(m-1) \cdot e_{J}\left(\sum_{i} q_{i}(0)\right)}{2} .
$$

Therefore, from (16), there exists $\bar{c}_{J}>0$ such that every entrant produces a positive output in equilibrium, provided $c \in\left(0, \bar{c}_{J}\right)$. Furthermore, $\bar{c}_{J}<1-Q_{I}^{*}$ as (16) also implies

$$
c<c+\frac{c(m-1) \cdot e_{J}\left(\sum_{i} q_{i}(0)\right)}{2}<1-\sum_{i} q_{i}(0) \leq 1-Q_{I}^{*}
$$

Finally, we characterize the interior solution condition of the incumbents. From (7), the interior solution condition for incumbents, $q_{i}(c)>0$, is equivalent to

$$
e(m)<\frac{2(a(m)-\theta(m) c)}{\theta(m) c(n-1)} .
$$

As $e(n) \rightarrow 0$ as $c \rightarrow 0$, there is $\bar{c}_{I}>0$ such that all incumbents produce a positive output in equilibrium provided that $c \in\left(0, \bar{c}_{I}\right)$, although the right-hand-side of (18) tends to $\infty$. Moreover, $\bar{c}_{I}<a(m, c) / \theta(m, c)$ because (18) does not hold if $c>a(m, c) / \theta(m, c)$. Define $\hat{c}=\min \left\{\bar{c}_{J}, \bar{c}_{I}\right\}$ to obtain the appropriate bound. By Lemma 3(a), every firm's second order condition of the optimal contracting problem is satisfied if $c \in(0, \hat{c})$.

\section{Proof of Proposition 2}

We first establish that $\kappa(m)$ is strictly increasing in $m$. Note that

$$
\kappa^{\prime}(m)=\frac{\left(4+c^{2}\right)(m+1)^{2}-4 c^{2} m^{2}}{\left[4(m+1)^{2}+c^{2}(m-1)^{2}\right]^{2}} .
$$

The numerator of the above expression is strictly positive if and only if

$$
\underbrace{\frac{4+c^{2}}{4 c^{2}}}_{h(c)}>\left(\frac{m}{m+1}\right)^{2} .
$$


Note that $h(c)$ is strictly decreasing on $[0,1]$ with $\min \{h(c)\}=h(1)=5 / 4>1$. The right-hand-side of the above inequality is always strictly less than 1 for $m \geq 1$. Hence, $\kappa^{\prime}(m)>0$. Next,

$$
\begin{aligned}
& a(m)=\frac{1-C_{1} \kappa(m)}{1-C_{2} \kappa(m)} \quad \Longrightarrow \quad a^{\prime}(m)=\frac{\left(C_{2}-C_{1}\right) \kappa^{\prime}(m)}{\left[1-C_{2} \kappa(m)\right]^{2}}=\frac{c\left(8+c^{2}\right) \kappa^{\prime}(m)}{2\left[1-C_{2} \kappa(m)\right]^{2}}>0, \\
& \theta(m)=\frac{1}{1-C_{2} \kappa(m)} \quad \Longrightarrow \quad \theta^{\prime}(m)=\frac{C_{2} \kappa^{\prime}(m)}{\left[1-C_{2} \kappa(m)\right]^{2}}=\frac{\left(4+c^{2}\right) \kappa^{\prime}(m)}{\left[1-C_{2} \kappa(m)\right]^{2}}>0 .
\end{aligned}
$$

It follows from Lemma 3(c) that $e(m)$ is strictly increasing in both $a(m)$ and $\theta(m) c$, and hence, the proposition.

\section{Proof of Proposition 3}

The proof directly follows from Lemma 3(c) with $A=A(m), B=B(m)$, and $N=n$.

\section{Proof of Corollary 1}

The corollary follows directly from Proposition 3. Because $e(n, m)$ is strictly decreasing in $n$ by Proposition 3, and $e^{\operatorname{sim}}(n+m)=e(n+m, 0), e^{\operatorname{sim}}\left(n+m^{\prime}\right)<e^{\text {sim }}(n+m)$ for every $m^{\prime}>m$.

\section{Numerical implementation}

In order to show that the incumbents expected output at equilibrium is increasing in the number of entrants, and the validity of Implications 2 and 3 in Section 5.2, we compute the model numerically. We define a grid over the parameter space $(c, n, m) \in \mathscr{C} \times \mathscr{N} \times \mathscr{M}$, where $\mathscr{C}$ is a grid of $(0,1)$ with each cell of size $c^{*}=7.6893 \mathrm{e}-6, \mathscr{N}=\{1,2, \ldots, 50\}$, and $\mathscr{M}=\{0,1, \ldots, 50\}$. For each $(n, m) \in \mathscr{N} \times \mathscr{M}$, we solve numerically for the upper bound of $c$, given by $\hat{c}(n, m)$. We then show the validity of the claims in every point in the parameter grid with $c \leq \hat{c}(n, m)$, accordingly. The cell size is given by: $c^{*} \equiv 0.5 * \min _{(n, m) \in \mathscr{N} \times \mathscr{M}}\{\hat{c}(n, m)\}$.

\section{References}

Allen, Beth, Raymond Deneckere, Tom Faith, and Dan Kovenock (2000), "Capacity precommitment as a barrier to entry: A Bertrand-Edgeworth approach.” Economic Theory, 15, 501-530.

Crawford, Anthony, John Ezzell, and James Miles (1995), "Bank CEO pay-performance relations and the effects of deregulation." Journal of Business, 68, 231-256.

Cuñat, Vicente and Maria Guadalupe (2009a), "Executive compensation and competition in the banking and financial sectors." Journal of Banking and Finance, 33, 495-504.

Cunat, Vicente and Maria Guadalupe (2009b), "Globalization and the provision of incentives inside the firm: The effect of foreign competition.” Journal of Labor Economics, 27, 179-212. 
Dasgupta, Sudipto, Xi Li, and Albert Y Wang (2017), "Product Market Competition Shocks, Firm Performance, and Forced CEO Turnover.” The Review of Financial Studies, 31, 4187-4231.

Daughety, Andrew (1990), "Beneficial concentration.” The American Economic Review, 80, 1231-1237.

Golan, Limor, Christine Parlour, and Uday Rajan (2015), "Competition, managerial slack, and corporate governance.” The Review of Corporate Finance Studies, 4, 43-68.

Grossman, Sanford and Oliver Hart (1983), "An analysis of the principal-agent problem.” Econometrica, $51,7-45$.

Hart, Oliver (1983), "Market mechanism as an incentive scheme." The Bell Journal of Economics, 14, $366-382$.

Hermalin, Benjamin (1992), "The effects of competition on executive behavior." The RAND Journal of Economics, 23, 350-365.

Hermalin, Benjamin (1994), "Heterogeneity in organizational form: Why otherwise identical firms choose different incentives for their managers.” The RAND Journal of Economics, 25, 518-537.

Hicks, John (1935), "Annual survey of economic theory: The theory of monopoly." Econometrica, 3, $1-20$.

Hubbard, R. Glenn and Darius Palia (1995), "Executive pay and performance: Evidence from the U.S. banking industry." Journal of Financial Economics, 39, 105-130.

Karuna, Christo (2007), "Industry product market competition and managerial incentives." Journal of Accounting and Economics, 43, 275-297.

Kole, Stacey and Kenneth Lehn (1999), "Deregulation and the adaptation of governance structure: The case of the U.S. airline industry.” Journal of Financial Economics, 52, 79-117.

Kreps, David and Jose Scheinkman (1983), "Quantity precommitment and Bertrand competition yield Cournot outcomes." The Bell Journal of Economics, 14, 326-337.

Legros, Patrick and Andrew Newman (2014), "Contracts, Ownership, and Industrial Organization: Past and Future." Journal of Law, Economics, and Organization, 30, i82-i117.

Leibenstein, Harvey (1966), "Allocative efficiency vs. X-efficiency." The American Economic Review, $56,392-415$.

Martin, Stephen (1993), "Endogenous firm efficiency in a Cournot principal-agent model." Journal of Economic Theory, 59, 445-450.

Nickell, Stephen (1996), "Competition and corporate performance." The Journal of Political Economy, 104, 724-746.

Palia, Darius (2000), "The impact of regulation on CEO labor markets." The RAND Journal of Economics, 31, 165-179.

Piccolo, Salvatore, Marcello D’Amato, and Riccardo Martina (2008), "Product market competition and organizational slack under profit-target contracts." International Journal of Industrial Organization, 26, 1389-1406. 
Raith, Michael (2003), "Competition, risk, and managerial incentives." The American Economic Review, 93, 1425-1436.

Scharfstein, David (1988), "Product-market competition and managerial slack." The RAND Journal of Economics, 19, 147-155.

Schmidt, Klaus (1997), "Managerial incentives and product market competition." The Review of Economic Studies, 64, 191-213.

Smith, Adam (1776), An Inquiry into the Nature and Causes of the Wealth of Nations. W. Strahan and T. Cadell, London.

Van Reenen, John (2011), "Does competition raise productivity through improving management quality?” International Journal of Industrial Organization, 29, 306-316.

Wu, Yanhui (2017), “Incentive contracts and the allocation of talent.” The Economic Journal, 127, 27442783. 